\title{
Towards an Integrated Egress/Evacuation Model Using an Open Systems Approach
}

\author{
HAMISH A. MACLENNAN \\ School of Building Studies \\ The N.S.W. Institute of Technology, Australia
}

\section{ABSTRACT}

Egress Research is fragmented through being too narrowly focussed. This research can be categorised into Behaviour and Movement. The Paper discusses the various evacuation models available and how they have not made the necessary allowances for all the aspects of egress. A new model. in the process of development is briefly discussed that will use an open systems approach to egress from buildings.

\section{INTRODUCTION}

Egress research appears to have been focused into narrow compartments (Pauls 1984). Stahl and Archea (1977) identified these areas prior to this as being;

1. Field studies of the use of circulation facilities in non emergency conditions;

2. Laboratory studies (eg. sign visibility in smoke);

3. Post incident surveys of human behaviour in emergencies.

The results of the studies are well recorded in the literature. They are still somewhat fragmented, but have been reviewed and compared with codes by such writers and researchers such as Stahl and Archea (1977), Pauls (1984), and Stah1, Crosson and Margulis (1982). Fragmentation can be overcome via integration. Certain models have already been developed, but the writer would maintain that the only valid ones will be those which view egress and/or evacuation as an open system so that all aspects of egress in an emergency environment can be assessed. The Search and Rescue Model (Alvord-1983) developed by the National. Bureau of Standards seems to have adopted this approach in part. Stahl's model B Fires II (1980) adopts a slightly different approach. Its implemtnation is somewhat complex because of the number of variables.

The author is in the process of developing a total model which will be known as the P.M.S. Model. The latter has been outlined in at least three papers (Maclennan 1984, 1985a, 1985b). It is being developed as part of a research programme for the Australian Uniform Building Regulation Co-ordinating Council and also as part of MacLennan's doctoral programme at Portsmouth Polytechnic. The Model will also incorporate additional areas of research such as;

1. Exit Affiliation Sime (1984a, 1984b)

2. Orientation and Wayfinding (Weisman Oze1, 1984)

3. Aspects of Visual Access which could be adapted from the work of Archea (1984) 
4. Tmplications of behavioural research that will permit confident generalisations to be made especially in terms of sequence keating and Loftus (1984) and as described by sime (1984b) re the contribution of his former colleague Breaux.

5. Importance and relevance of Rerceived Time Needed and Perceived Time Available sime (1984b).

The main problem of the behavioural component of the Model is one of sequence and the prediction of times. A possible answer will be presented in a later section of this paper.

Models Available

A number of egress models have already been developed viz;

1. Evachet :

R.L. Francis of the University of Florida

2. Search and Rescue:

D.M. Alvard; National Bureau of Standards

3. B Fires II

F.I. Staht formerly of the National Bureau of Standards

4. Descriptive Model: E. Kendik for Movement

5. Effective Width Model

: J.L. Pauls, National Research Council of Canada.

The most powerful of these models in terms of movement is Evacnet. In the writer's opinion it only deals with part of the problem, seeing it does not really cater for human behaviour in terms of time. Human Behaviours such as perception of cues, investigation for the purpose of seeking information and general coping behaviour that may not involve actual movement towards exits or along egress routes are not really included. The time associated with these behaviours could be classified as start up time (ST). Once the decision has been made to evacuate an area then individuals or groups of individuals would move towards the exits. This time could be termed (MT). The latter could be defined as the time taken for occupants to reach an exit. There are however, still problems associated with;

(a) Orientation and wayfinding (Weisman/Ozel 1984)

(b) Exit affiliation (Movement towards the familiar)

(Sime 1984a) ana hence exit choice

(c) Pexceived time needed and available that could affect both (ST) and $(M T)$

The time from initial perception to exit access could be sumarised as being the clearance time for an area (CT). Evacnet could be modified to cater for this in certain occupancies such as assembly buildings. This is, however, an oversimplification of the problem. It does not allow for the cyclic relationship between behaviour and movement. Movement through exit systems has been well researched by Pauls, Fruin and others. The Search and Rescue Model has partly overcome the problem, but it is only really suitable at present for Board and Care Homes: It too has potential for other occupancy types, where there is an evacuation plan and team. B. Eires II is a simulation model but its main problem is complexity in terms of the number of variables. Kendik and Pauls' models only address movement through exits in the main. The writex would maintain that there is a need for a model that is based on a systems approach as developed in management science. The egress problem can be visualised as being a management exercise be it self management or group management. The impact of the environment at large together with the emergency environment must be catered for and identified. 
Prediction of the Required Safe Time for Egress (RSET)

Available Time for Egress. Cooper (1983) postulated that the available safe egress time (ASET) in enclosure fires is defined as the time between fire detection and the onset of conditions which are hazardous to continued human occupancy. The other side of the equation is RSET. Cooper (1983) defines this as being the length of time, subsequent to alarm, which is actually required for safe occupant egress from threatened spaces. This definition is valid however in certain occupancy types such as assembly building where the population density and the evacuation plan are such that egress is almost entirely movement controlled eg. stadia. Sime (1984b) is concerned with detection in terms of time. He discusses the problem of perception in terms of the time that people think they have available PrA and the time they think they need to evacuate the building safety (PTN). These times can be related directly to cues especially in terms of whether they are ambiguous or unambiguous. It is therefore imperative that RSET be related to ASET in terms of cues. Cooper's model deals mainly with single room or compartment fires.

There are other models that have been developed that go beyond ASET such as FAST (Model for the Transport of Fire Smoke and Toxic Gases (Jones 1984). Jones maintains that it is necessary from a life safety and operational standpoint to be able to make accurate predictions of the spread of fire, smoke and toxic gases. This will in turn provide valuable inputs for an egress model in terms of time available in spatial terms. This can then be related to the actual layout and/or configuration of various building types together with the resultant egress behaviour. FAST also opens up possibilities according to Jones for combatting the various problems that may arise as well as taking preventive measures. Much of this can be achieved through design intervention and "evacuation" planning. Other models have been developed such the Multi Room Elre Spread Model by Tanaka (1983) and a Two Room/Compartment Model by Zukowski and Kubota (1980). The Centre for Fire Research is currently developing a "family" of models that will. eventually address most instances and provide the necessary input for the various forms of egress/evacuation models in the form of constraints. The simple concept of the designed safe egress cxiterion basically still stands $v i z-$

RSET (thazard - taetection) < ASET

The problem is therefore one of confidently predicting RSET. The one component of RSET namely human behaviour is the one that poses the problem (Sime 1984b).

Generalisations about Human Behaviour that will permit Sequence and Time Predictions: The main researchers into Human Behaviour have been wood, Canter, Bryan and Keating. The work of wood $(1972,1980)$ and Bryan in Project people and Project People II are perhaps the most widely $x e a d$ and quoted. They provided the necessary start and in fact identified most of the actions and/or responses. Sime, Canter and Breaux also made valuable contributions (1980), and Sime demonstrated (1984b) the relevance of this work in terms of RSET. Their "decomposition" diagrams (1980) provided a valuable insight into the relationship between behaviours in emergencies. sime also raised problems associated with time and perception in terms of egress.

Keating and Loftus (1984) have developed a new interviewing technique known as the Behavioural Sequence Interview Technique. The main benefit of this work is that it will provide real. world answers and a data base which will eventually be large enough to allow confident generalisations about human reactions and behaviour during fires. When this technique is coupled with the work carried out by sime, Breaux and Canter (1980) and sime (1984a) together with work of Bryan and wood then the behavioural 
component will start to take shape. The writer intends to use this technique in a modified form to design questionnaires for use in evacuation drills that he will be carrying out as part of a research project (Maclennan 1984).

Movement. Movement of people along egress routes and through exits has provided sufficient data for the prediction of the movement phase of an egress model. Stahl and Archea 1977, Stah1, Crosson and Margulis (1982) and Pauls (1984) have already appraised the 1iterature. Kendik (1984) has developed a model based on the work of Predtechenskil and Milinski (1978). This "model" has vast potential for use within an integrated model. Kendik will be also examining the Evacnet and Effective Width Models as well this year, so that there could be further developments in this area. Maciennan intends to incorporate the results of this research into his model.

Other perameters have to be catered for such as the problems of orientation and wayfinding, group behaviour perception of additional cues and most important of all exit choice. The latter is a function of exit affiliation viz. movement towards the familiar (Sime 1984a). The study of oxientation and wayfinding (Weisman, ozel 1984) is in its infancy, but studies in non emergency conditions will (Passini) provide valuable information and data. Visual access is equally as important (Archea 1984) in terms of what features of building a person can see from a certain station within that building. When this is coupled with cognitive mapping and wayfinding then the problem with the spatial form and distribution of exits in relation to the normal circulation spaces could be more clearly stated.

Integrated Model for the prediction of RSET. The author is currentIy developing a model which will be known as the P.M.S. Model (Perception movement safety). Any model in this vein could be seen as being futile where it failed to view egress/evacuation as a system. The model views the occupants of a building as a form of organisation in event of an emergency. Certain types of building occupancy such as shops are frequented by the public who may not be familiar with the building. Occupants of office buildings could quite well be familiar with the building. This poses structural problems about the result "emergency organisation".

The environment at large is turbulent. "The environment" within a building during an emergency such as fixe is constantly changing so that it too is turbulent. "Oxganisations" within the building can no longer be isolated from each other and other external organisations which go to constitute the environmental world of interactions. The organisation must therefore be studied as a system especially in terms of:

1. Its component parts (incl. interaction)

2. Reaction/Interaction with the Environment and the resultant change

3. Setting of objectives

4. Input - Throughput - Output in terms of management effort to achieve objectives.

Organisations if they are to operate within a changing enviroment, must interact positively with that environment and modify their modus operandi as a result thereof. They must therefore be viewed as open systems seeing they are also similar to living systems in that in order to maintain themselves or "survive" (especially in emergencies) they must be constantly exchanging material, energy and information with the environment and modifying their goals (in part), behaviour, strategy, structure etc. Goals are extremely important in terms of reaction to and with the environment. They must be compatible if the organisation is to survive and hence the individuals within that organisation. 
The occupants of buildings comprise individuals. The latter may exist in groups comprising organisations or as members of the public. There is no set ratio between the two other than a broad range that would relate to the occupancy type. Even the number of organisations occupying an office building could vary depending on the tenancy strategy of building owner. The latter may even occupy the whole building in the form of one organisation. Whatever the profile may be, this may be modified in event of an emergency.

In an emergency such as a fire the "environment" is immediately modified. The occupants of the building axe therefore collectively "threatened". They receive certain cues, start to investigate them, seek information from others, carry out other coping actions, decide to evacuate, try to find their way to exits, encounter further cues, investigate further, assist others and the like. These behaviours may be structured depending on prior training and emergency management practices. The occupants in relating to one another and to the environment have comon objectives;

1. To find out what is "going on"

2. To escape safely or be assured that they will be safe as result of following a set of instructions which they perceive to be correct.

The occupants are spatially related. They therefore comprise an organisation. The evacuation of or egress from a builuing involves its occupants either individually or in groups reacting to cues from an emergency generated environment. The main objective for each occupant or for each group and in fact for ali groups is life safety. The achievement of such an objective is series of problem solving exercises. Problem solving is synonyuous with management practice. The writer is of the opinion that the systems approach can be used to accomplish this end i.e. organisations can be viewed as open systems.

The subsystems of an emergency organisation are seen as being;

1. Goals and Values: that of the "organisation" and its members related to emergencies which would be concerned with safety.

2. Structures: i.e. structuring of relationships, patterns of communication and information gathering plus the processing thereof, line of authority, level of responsibility and the like. Existing organisational hierarchies must therefore be considered.

3. Psychosocial: individual needs, motivation, behaviour, values, participation, perception of the environment, group dynamics and the like related to emergencies.

4. Technical: Ievel of knowledge in the main. This also relates to safety education and prior evacuation training. Specialist advice may often therefore be required.

5. Managerial: need for management and coordination of the organisation to achieve objectives e.g. safety "Throughput" is therefore critical. See Figure 2a.

All of the above subsystems are part of the "whole" i.e. the organisation. Each subsystem is related to the other. Systems theory allows these relationships to be clearly identified and analysed. Emergency situations seldom occur and exist within the life of a building. The occupants of a building therefore have little opportunity of functioning as an emergency organisation in a condition of emergency. Training is therefore an essential part of the management of emergency organisations.

Another problem that exists with buildings is in the design thereof. Architects and their consultants may not be entirely aware of the makeup 
of the "end users" of the building they are designing. If they carry out market research and determine their client's needs properly, then building safety can be taken into account. Building owners and Designers often consider that it is sufficient to merely comply with the provisions of the various codes. This could hardly be seen as being "design intervention". Each building is unique within itself together with its resultant impact on the end user.

The results of research in the area of egress and fire provide valuable input for any model concerned with life safety. These highlight the need for designers to cater for the needs of people. Fire protection and detection systems, smoke control systems, evacuation plans and procedures, location and use of exits, internal subdivision need to be designed around the use of the building and to satisfy the needs of the future occupants of the building. The P.M.S. model is being developed to allow both the owner and the designer to develop a full life safety strategy basea on the analysis of a special "organisation" functioning in an emergency environment. It will also allow for a similar type of analysis for existing buildings where life safety is inadequate.

The PMS Model is shown in systems format in figure one. It has been based on a similar management model developed by Kast and Rosenzweig (1978). The throughput has been analysed and summarised in a collapsed form in figures $2 \mathrm{a}$ and $2 \mathrm{~b}$. The operational flow is cyclic in nature as shown and has been developed as a result of discussions held in ottawa at the National Research Council of Canada between Messrs. Pauls and Maclennan and Dx. Sime. The components of the flow have been identified as Cues, Relatively Complex Behaviour, Direct Movement to and through exit and Safety. The diagram is simplistic and is virtually self explanatory. It will allow for the complete integration of the results of research of egress and the fire scenario within the various environmental constraints. The results of research clearly indicate the need for both management and responsible design intervention strategies to cater for life safety. There is a need for total involvement of people. If an organisation is seen as being dynamic then the open systems approach can be used and the psychosocial subsystem catered for. The Goals of the emergency organisation can be aligned with those of its members via an integrated Management approach such as "Management by objectives". The "emergency organisation" would then be established and the individuals in that organisation motivated to be concerned with safety via a safety comittee. Training via drills and education in the aspects of emergency scenarios such as fire would then be invaluable. Failure to adopt this approach could result in confusion. This would increase the overall time required for safe egress to the point where it exceeded the time available.

Relatively complex behaviour as a component of the throughput includes the detection of a cue, investigation and the seeking of further information, other forms of coping behaviour including fire fighting, the decision to evacuate and assisting and warning others. The Direct Movement to Exits Component includes the movement aspect, oxientation and wayfinding, exit choice and affiliation, visual access, receipt of further cues which would alter the flow as shown in figure $2 \mathrm{a}$ and eventually movement along egress routes through exits to safety. It also highlights the fact that evacuation may not be the safest solution and that the objective of safety may be accomplished by other means such as rescue. The flow for any situation could be set down in a predetermined safety or emergency plan. The flow of information within the organisation and hence through the builaing in spatial terms is therefore vital. The Model is therefore seen as being an integrated approach for the achievement of the life safety objective and hence the prediction of RSET as applicable. 
JNPUT: FALLS INTO TWO CATECORIES

1. FROM GENERAL ENIVIRONMENT

- KNOWLEOCE RE FIRE SCENARRIO

- pricor trajkina

- fire protection/petection/ safety

- other

2. FROM EMERCENCY ENVIRONMENT

REFERS TO ACTUAC INTERNAL ENMRONMENT DURING

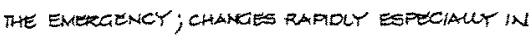
EVET OFFIRE; IT PROVIDES HE WNTALC CLES.

THE P.M.S. MODEL.

(PERCEPTON/MOVEMENT/SAFTY)

Figure 1
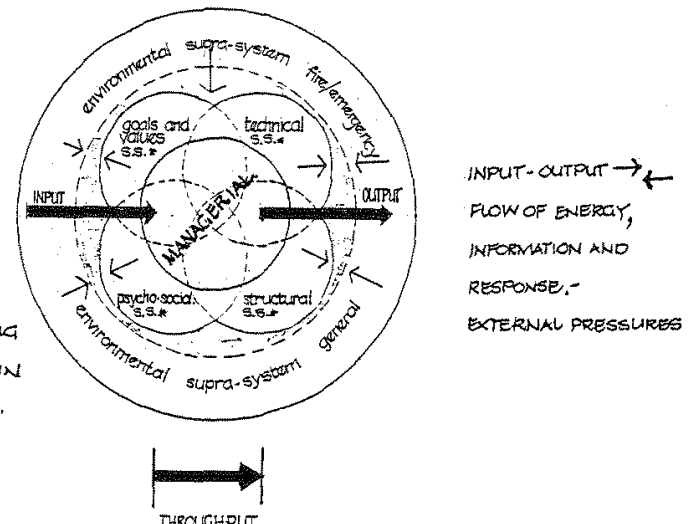

OUTPUT: ACHIEVEMENT OF SAFETY OEUEGIVE.

1. ESCMFE TO OREN SFACE

2. ESCAPE TO AREA OF REFUGE

3.NO ACTLN; EMERGENCY BRCUKHT UNDER CONIROL OR RESCLE EFFECTED.
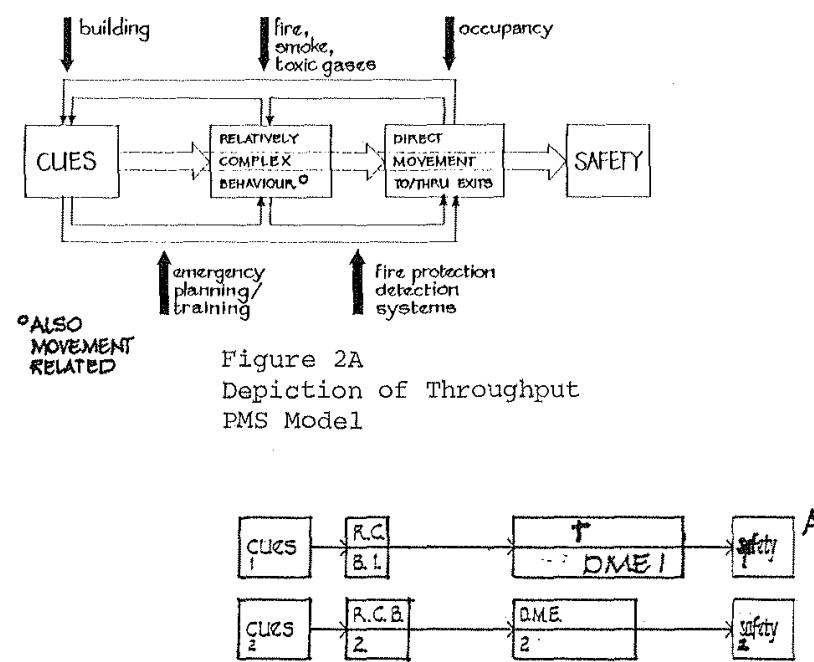

\begin{tabular}{|c|c|c|c|}
\hline \multirow{2}{*}{ gues } & $R \subset 3$. & QME & \multirow{2}{*}{ (19fot) } \\
\hline & 3. & 3 & \\
\hline
\end{tabular}

\begin{tabular}{|c|c|c|c|}
\hline & $R<3$ & QME & oste \\
\hline 4 & 4 & 4 & $\Delta^{4}$ \\
\hline
\end{tabular}

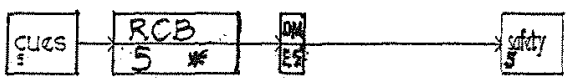

sth

TDRECT MOVEMENT TO/THRU EATS * RELATIVELY-COMPLEX eEHaVIOUR

\section{Figure 2b}

Time Variability by component and Occupancy TypePMS Throughput Model.

ASSEMBLY

ocaparty typ !

ocuparcy type 2

conparcy types.

ocaparcy typed.

APARTMENTS araparty wpots 
The Estimation of Times for the RCB and DME Portions of the Throughput of the PMS Model. The current data available from Research into Human Behaviour cannot be used to make accurate generalised predictions. BSIT as developed by Loftus and Keating (1984) could overcome this problem when viewed in conjunction with work carried out by Canter Breaux and sime (1980) (Sime 1984b). It identifies sequence hence permitting data derived from this technique to be used in making accurate generalised predictions re sequence. Activities could be "sequenced", but there will still be the problem with estimating times. The Australian Research study will utilise this approach in the design of evacuation drills. Maclennan is aware that these drills will not be under emergency conditions, but each building that is to be evacuated will be operated in "fire mode". Sime, Pauls and Maclennan are in the process of developing a questionnaire that will follow the concept of BSIT. The net result will be the development of data that can be analysed in association with other existing data and that can be used to estimate times for each generalised activity. These sequences will then be integrated to derive an overall time which will be matched against the appropriate fire growth or smoke production/filling/movement models.

This problem does not exist to the same extent with the DME portion of the throughput, as previously discussed. Effects of orientation and wayfinding, exit affiliation, visual access and the like will also be identified together with the effect of faulty design intervention strategies on the questionnaire. Dixect observation techniques such as those used by pauls (1980) will be used to reinforce and/ox supplement the questionnaire.

The objectives of the throughput should be;

1. The prediction of a total RSET.

2. The comparison of RSET with "ASET" at strategic points (not necessarily Cooper's version).

3. The evaluation of the degree of safety associated with each building analysed.

4. The identification of areas requiring design intervention and adoption/ modification of emergency management and training procedures.

5. Adequacy of Building Codes re Life Safety.

6. Framework for the improved design of egress systems and management.

\section{CONCLUSION}

Research will be constantly making progress with each year. Data will and is becoming more reliable especially in the area of human behaviour. Models will be able to utilise this data coupled with that of the movement phase of egress so that the preaiction of a total egress time can be made. The P.M.S. Model will endeavour to achieve this end seeing it uses a systems approach.

\section{REFERENCES}

1. Alvord, G.: Status Report of Escape and Rescue Mode1, NBS-GCR-83-432, Washington, June 1983, National Bureau of Standards.

2. Bryan, J.I.: An Examination and Analysis of the Dynamics of Human Behaviour in the M.G.M. Grand Hotel Fire, Clark County, Nevada, November 21, 1980, National Fire Protection Association, Revised Edition, April, 1983.

3. Bryan, J.I.: Smoke as a Determinant of Human Behaviour in Fire Situations (Project People), Center for Fire Research, National Bureau of Standards, 
Program for Design Concepts, Grant No. 4-9027, 1977.

4. Bryan, J.I.: Implications for Codes and Behaviour Models from the Analysis of Behaviour Response Patterns in Fire situations as selected from the Project People and Project People II study Programs, NBS-GCR83-425, Washington, National Bureau of Standards, March 1983.

5. Bryan, J.L.: The Determination of Behaviour Response Patterns in Fire Situations, Project People II, Final Report - Health Care, NBS-GCR-81343, Washington, National Bureau of Standards, September 1981.

6. Canter, D., Breaux, J.J. and Sime J.D.: "Domestic Multiple Occupancy and Hospital Fires" in D. Canter (Ed.), Fires and Human Behaviour, Ch. 8, pp.117-136, Chichester New York, J. Wiley and Sons, 1980.

7. Collins, B.I. and Lemer, N.D.: An Evaluation of Exit Sign Visibility, Final Report, NBSIR 83-2675, Washington, National Bureau of Standards, Apri1, 1983.

8. Cooper, I.Y.: "A Concept for Estimating Available Safe Egress Time in Eires" in Fire Safety Journal, vol. 5, pp.135-144, 1983.

9. Fruin, J.J.: Pedestrian Planning and Design, Metropolitan Association of Urban Designers and Environmental Planners, New York, 1971, (currently under revision - 1985).

10. Herz, E., Edelman, P. and Bickman, I.: The Impact of Fire Emergency Training on Knowledge of Appropriate Behaviour in Fires, NBS-GCR-78-137, National Bureau of Standards, Washington, January 1979.

11. Hunt, J.W.: The Restless Organisation, John Wiley and Sons Ltd., Sydney, 1976.

12. Jones, W.J. and Quintiere, J.G.: "Prediction of Corridor Smoke Filling by zone Models", in Combustion Science and Technology, 1983, Vol. 11, Gordon and Breach Science Publishers Inc., London, 1983.

13. Jones, W.J., A Model for the Transport of Fire, Smoke and Toxic Gases (FAST), NBSIR 84-2934, Gaithersburg, Maryland, National Bureau of standards, september, 1984.

14. Kast, F.E. and Rosenzweig, J.E., organisation and Management, Systems Approach, 3rd Edition, McGraw-Hi11 Kogakusha Ltd., Tokyo, 1978.

15. Keating, J.P. and Ioftus, E.F., Post Fire Interviews: Development and Field Validation of the Behavioural Sequence Interview Technique, NBSGCR-84-477, Gaithersburg, National Bureau of Standards, October 1984 .

16. Kendik, E.: "Assessment of Escape Routes in Buildings - Discussion of a Design Method for Calculating Pedestrian Movement", Paper presented at a Fire Conference held at the center for Fire Research, National Bureau of Standards, Gaithersburg, Maryland on the 18th October 1984, unpublished.

17. Levine, M.: "Cognitive Maps and You-are-here Maps", Article based on address presented to the A.P.A., Washington, D.C., $1 \overline{982}$, State University of New York at New York.

18. Mactennan, H.A.: "Current Research Relating Time Required and Time Available for Egress", Paper presented at the Speakers' Session No. 4; 
"Evacuation Time Criteria for Buildings - what do we know about the Time Needed and the Time Available?", Fall Meeting, National Fire Protection Association, San Diego, November, 1984.

19. Maclennan, H.A.: "The Problem with Estimating the Safe Time Required for Egress", Paper submitted and accepted for the ASHRAE National Meeting to be held in Honolulu, Hawaii, 23rd-27th June 1985. (1985a).

20. Maclennan, H.A.: Paper submitted and accepted for the International Conference on Building Use and Safety to be held in Los Angeles, 12thl4th March 1985, Building Use and Safety Institute and the National Institute of Building Sciences, Washington, D.C., (1985b).

21. MacLennan, H.A.: (On Management and Organisation Theory), unpublished Lecturer Notes, Building Degree Course, Faculty of Architecture and Building the New South Wales Institute of Technology, N.S'W., Australia, 1976-1978.

22. Pauls, J.L.: "The Movement of People In Buildings and Design solutions for Means of Egress", in Fire Technology, Vol. 20, 1984, pp.27-47.

23. Pauls, J.I.: "Building Evacuation: Research Findings and Recommendations", in D. Canter (Ed.), Fires and Human Behaviour, Chichester/New York, Wiley, 1980, Ch. 4, pp. 251-276.

24. Pauls J.L., Sime, J.D. and Maclennan, H.A.: Private Communication and Discussion, National Research Council of Canada, Ottawa, November, 1984.

25. Sime, J.D.: "Movement towards the familiar: Person and Place Affiliations in a Fire, Entrapment Setting", published in Duerk, D. and Campbell, D., (Eds.), The Challenge of Diversity: Proceedings of EDRA/15, 1984, Environmental Design and Research Organisation, Washington, D.C., pp.100-109, 1984a.

26. Sime, J.D.: "Psychological and Social Factors Influencing and Evaluation", Paper presented at the Speakers' Session No. 4; "Evacuation Time Criteria for Buildings - What do we know about the time needed and the time available?", Fall Meeting, National Fixe Protection Association, San Diego, November $1984 \mathrm{~b}$.

27. Stahl, F.I. and Archea, J.C.: An Assessment of the Technical Literature on Emergency Egress Behaviour during Fires, Calibration and Analysis, NBSIR 79-1713, National Bureau of Standards, Washington D.C., 1977.

28. Stah1, F.I., Crosson, J.J. and Marguus, S.T.: Time-based Capabilities of occupants to Escape Fires in Public Buildings: A Review of Code Provisions and Technical Literature, NBSIR 82-2480, National Bureau of standards, Washington D.C. 1982.

29. Stahl, F.I.: "BFIRES/VERSION 2: Documentation of Program Modifications", NBSIR 80-1982, 1980, Washington D.C., National Bureau of Standards.

30. Tanaka, T.: A Model of Multi Room Fire Spread, Published as a NBSTR, National Bureau of Standards, Washington, 1983.

- 31. Wiseman, G.D. and ozel, F.: "Way Finding, Cognitive Mapping and Fire Safety: Some Directions for Research and Practice", paper submitted to the Environmental Design and Research Organisation, Annual Conference, San Luis Obispo, California, June-July 1984, University of Winsconsi, Milwaukee, 1984.

32. Wood, P.G.: "A Survey of Behaviour in Fires", in Canter D., (Ed.), Eires and Human Behaviour, John Wiley and Sons Ltd., Chichester/New York, 1980, pp.83-95.

33. Zukowski, E.E. and Kubota, T.: "Two Layer Modelling of Smoke Movement in Building Fires, Fire and Materials 4, 17, 1980. 